\title{
0 Futuro dos Plásticos: Biodegradáveis e Fotodegradáveis
}

\author{
A busca por soluções que levem a um plástico descartável ideal vem mobilizando cientistas e ambientalistas há algum \\ tempo. As pesquisas apontam na substituição dos plásticos convencionais por plásticos biodegradáveis e fotodegradáveis, \\ uma vez que segmentos de mercado que apresentam uma grande conscientização da população pela preservação do \\ meio ambiente, se disponibilizam a pagar a mais por um produto não poluidor, resultando daí ganhos ambientais, \\ econômicos e sociais. \\ A Revista "Polimeros" apresenta nesta edição dois estudos de pesquisadores brasileiros que procuram fazer suas pesquisas \\ voltadas para a melhoria da qualidade de vida.
}

\section{Plástico Biodegradável preparado a partir de Amido}

Nos últimos anos, vários países em todo o mundo têm reconhecido a necessidade de se reduzir à quantidade de materiais plásticos desperdiçados e descartados, além de incentivarem a reciclagem, que apesar de depender, em grande parte da coleta e seleção do produto, e apesar de grande parte dos municípios brasileiros possuírem algum tipo de coleta seletiva, não atingem a totalidade de recicláveis. Neste contexto, o interesse na utilização de produtos que tenham origem vegetal e a produção de materiais, principalmente plásticos com caráter biodegradável tem se intensificado como política em diversos setores da sociedade.

Em face ao contexto atual, uma nova tecnologia vem revolucionando o mercado de descartáveis: é o amido termoplástico, que é produzido a partir do amido. $\mathrm{O}$ amido, reserva de alimentos de plantas como o milho, arroz, mandioca, entre outras, é encontrado abundantemente na natureza graças ao cultivo extensivo e intensivo de cereais, é renovável, possui custo relativamente baixo, é um importante segmento da economia e pode ser convertido química, física e biologicamente em compostos úteis à indústria. $\mathrm{O}$ amido, sob pressão e temperatura, e na presença de um agente plastificante, pode ser gelatinizado, e sob efeito de cisalhamento se transformar em um fundido. Este material é denominado amido termoplástico.

O estudo para o emprego do amido termoplástico na substituição do plástico convencional (de origem petroquímica) destinado a algumas aplicações específicas vem ganhando força e recebendo considerável atenção no cenário dos recursos renováveis. Pode ser empregado como saco de lixo, filmes para proteger alimentos, fraldas infantis, hastes flexíveis com pontas de algodão para uso na higiene pessoal; na agricultura vem sendo empregado como filme na cobertura do solo e recipientes para plantas. Também pode ser usado na preparação de cápsulas, na substituição do poliestireno expandido (ISOPOR ${ }^{\circledR}$ ) na proteção de equipamentos durante o transporte; na produção de talheres, pratos e copos descartáveis, na fabricação de canetas, lapiseiras, brinquedos e outras aplicações onde o caráter biodegradável seja requerido.

Com o intuito de se estudar, entender, aperfeiçoar e inovar o amido termoplástico, vários pesquisadores têm trabalhado nesta área. Na Universidade de São Paulo, no campus de São Carlos, atualmente são desenvolvidos três estudos sobre o amido termoplástico, todos com financiamento da Fundação de Amparo a Pesquisa do Estado de São Paulo (FAPESP), sendo dois deles sob orientação do Prof. Dr. Antonio Aprígio da Silva Curvelo (Instituto de Química de São Carlos) e um sob orientação do Dr. Luis Henrique Capparelli Mattoso (Embrapa). Um dos doutoramentos é realizado no estudo da utilização de novos plastificantes aplicados à preparação do amido termoplástico, desenvolvido pela doutoranda Alessandra Luzia Da Róz; um segundo estudo visa o emprego de proteína derivada do milho (zeina) e amido termoplástico na preparação de blendas, realizado pela doutoranda Elisângela Corradini. Estes dois trabalhos são desenvolvidos junto ao Programa de Pós-Graduação Interunidades em Ciência e Engenharia de Materiais. Um terceiro trabalho é o estudo da incorporação de lignina em amido termoplástico, desenvolvido pelo doutorando Luis Carlos de Morais, junto ao Instituto de Química de São Carlos. O primeiro trabalho já concluído neste tema estudou o reforço de amido termoplástico utilizando fibra vegetal, defendido recentemente pelo Dr. Antonio José Felix de Carvalho, também pelo Programa de Pós-Graduação Interunidades em Ciência e Engenharia de Materiais.

No estudo de novos plastificantes empregados na preparação de amido termoplástico, a doutoranda Alessandra utiliza amido de milho em mistura com diversos glicóis e procede ao processamento da mistura em um misturador intensivo, com tempo e temperatura controlados. Após o processamento o amido termoplástico é submetido à prensagem, de onde se obtém corpos de prova para a realização de diversas análises, inclusive análises mecânicas para avaliação das propriedades e características deste novo material. Além da pesquisa acima citada, Alessandra está estudando, por meio de modificações químicas do amido, a diminuição da natural absorção de água apresentada pelo amido, o que conseqüentemente afeta as propriedades dos amidos termoplásticos. A tecnologia para a produção do amido termoplástico vem sendo estudada e algumas empresas estrangeiras, como a Novamont, já estão produzindo e comercializando filmes e peletes de blendas de amido termoplástico.Produtos obtidos exclusivamente de amido termoplástico são mais baratos que os plásticos 
sintéticos derivados de petróleo e possuem a vantagem adicional de serem biodegradáveis. Adicionalmente, o amido termoplástico é compostável e pode ser processado nos mesmos equipamentos tradicionalmente empregados para o processamento dos plásticos convencionais.

Como conseqüência dos resultados já obtidos pelos trabalhos realizados junto ao Programa de Pós-Graduação do Instituto de Química de São Carlos e do Programa Interunidades em Ciência e Engenharia de Materiais, ambos da Universidade de São Paulo, já foram depositadas duas patentes junto ao INPI, havendo também o interesse manifesto de indústrias na produção e comercialização de produtos derivados de amido termoplástico.

Alessandra Luzia Da Róz USP/Instituto de Química de São Carlos

\section{Plástico degradável com luz solar}

Um plástico revolucionário no mercado, que se deteriora com a luz solar e pode reduzir a poluição no meio ambiente foi desenvolvido - e patenteado no ano passado - por cientistas do Instituto de Química da UNICAMP. Trata-se do plástico fotodegradável, uma mistura de polietileno - muito usado em embalagens e sacolas - com um polímero orgânico, se decompõe pelo menos duas vezes mais rápido que o plástico comum, que se desfaz em 20 a 30 anos.

O material é resultado da dissertação de Mestrado do pesquisador Ralf Giesse, sob orientação do Prof. Dr. Marco-Aurelio De Paoli do Instituto de Química da UNICAMP. As propriedades do plástico foram descobertas por acaso, quando estudava-se a alteração das propriedades de barreira do polietileno. Queria-se checar se o segundo componente - o polímero orgânico - alterava a permeabilidade do polietileno a diferentes gases. Quando o material foi submetido à radiação ultravioleta por longos períodos de tempo, verificou-se que ele ficava amarelado muito antes que o polietileno puro de mesma espessura. Amostras de um filme de polietileno comum e de plástico fotodegradável foram submetidas a 300 horas de irradiação sob uma lâmpada ultravioleta. Ao final do experimento, verificouse que o polietileno comum estava ligeiramente amarelado, enquanto a mistura de polietileno com o polímero orgânico estava bem amarelado e quebradiço, ou "fotodegradado".

O segundo componente do plástico fotodegradável - o polímero orgânico "secreto" - fica disperso na estrutura do plástico e atua como acelerador do processo de degradação. Com a adição do segundo componente, o tempo de decomposição do material cai pela metade. No final do processo total de degradação, o material acaba voltando à natureza, inclusive sob a forma de dióxido de carbono.

O Prof. De Paoli ressaltou a importância de reduzir o impacto ambiental, causado pelo descarte inadequado de plásticos, comentando que a solução a curtíssimo prazo é a reciclagem do produto; a solução a médio prazo é o uso de plástico fotodegradável e a solução a longo prazo é o uso de plástico biodegradável. No Brasil, são descartadas mais de 100 toneladas por ano de resíduos sólidos e os polímeros representam quase $10 \%$ deste total.

O novo produto já obteve licença de patente, em agosto do ano passado, pelo Instituto Nacional de Propriedade Industrial (INPI) e recebeu o prêmio de menção honrosa, em novembro do mesmo ano, no Prêmio Governador do Estado de São Paulo "O Invento Brasileiro", fornecido aos principais inventos patenteados no Brasil. Algumas empresas já estão interessadas em adotar o plástico fotodegradável em suas linhas de produção, mas não houve, ainda, pedido de licença concedido pela Unicamp.

Ralf Giesse

UNICAMP/Instituto de Química

\section{A todos os nossos associados, fornecedores e amigos que contribuíram para que a ABPol continuasse a ser um sonho realizado, Boas Festas e que 2004 seja um ano de intensos momentos de Harmonia, Paz e Prosperidade.}
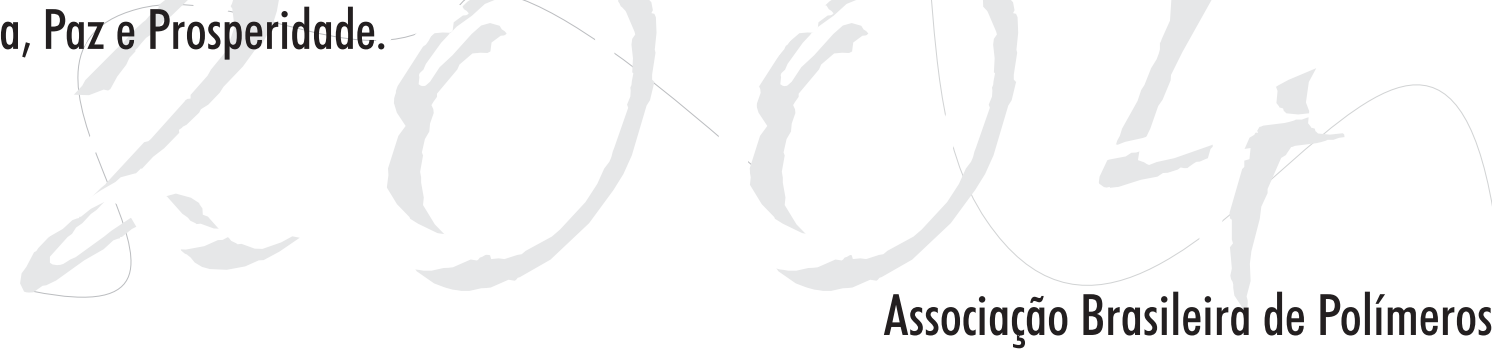


\section{PROPAGANDA BASF}

